\title{
Metabolic Fate of Arachidonic Acid in Hepatocytes of Continuously Endotoxemic Rats
}

\author{
Elena B. Rodriguez de Turco and Judy A. Spitzer \\ Department of Physiology, Louisiana State University Medical Center, New Orleans, Louisiana 70112
}

\begin{abstract}
The present experiments were designed to characterize the kinetics of $\left[1-^{14}\right.$ Clarachidonic acid (AA) metabolism as a function of time in hepatocytes obtained from rats infused continuously for $\mathbf{3 0} \mathrm{h}$ with a nonlethal dose of Escherichia coli endotoxin (ET). Chronic endotoxemia greatly reduces the ability of hepatocytes to utilize $\left[1-{ }^{14} \mathrm{C}\right] \mathrm{AA}$, which is reflected from the earliest times of incubation in very low labeling of intermediates in the biosynthetic pathways of glycerolipids (phosphatidic acid and diacylglycerol) and slower removal of $\left[1-{ }^{14} \mathrm{C} A \mathrm{AA}\right.$ from the free fatty acid pool as compared with saline-infused rats. At later times of incubation, the labeling of phospholipids (especially phosphatidylethanolamine and phosphatidylinositol [PI]), but not of triacylglycerides is decreased. Analysis of fatty acid composition of individual phospholipids from cells of ET-infused rats reveals that the content of $A A$ is significantly reduced only in PI. Hence an impairment in activation/acylation enzymatic mechanisms could affect the turnover of metabolically active phospholipid pools, i.e., PI, involved in signal transmission processes, and result in increased availability of 20:4 for eicosanoid synthesis, contributing to cellular metabolic perturbations in endotoxicosis.
\end{abstract}

\section{Introduction}

Arachidonic acid (AA), the precursor for a variety of mediators of cell function (i.e., eicosanoids) is stored esterified at the sn-2 position of cellular phospholipids. The pathways of AA metabolism are outlined in Fig. 1. Under resting conditions the arachidonate turnover is regulated by the coupled activities of phospholipase/acyltransferase, a dynamic cycle that accounts for most of the arachidonate incorporated into these lipids (1, 2). The activity of AA-coenzyme A ester (CoA $)^{1}$ :lysophospholipid acyltransferase is considered as the enzymatic pathway committed to the maintenance of cellular very low basal levels of free AA (2). In activated cells this dynamic equilibrium can be displaced toward the release of AA through the stimulation of degradative processes that involve phospholipase $A_{2}$ and/or

Received for publication 18 May 1987 and in revised form 27 August 1987.

1. Abbreviations used in this paper: CoA, coenzyme A; DG, diacylglycerol; ET, E. coli endotoxin; PA, phosphatidic acid; PC, phosphatidylcholine; PE, phosphatidylethanolemine; PI, phosphatidylinositol; PL, phospholipid; PS, phosphatidylserine; TG, triacylglycerol. Fatty acids are abbreviated according to convention-number of carbon atoms:number of double bonds.

J. Clin. Invest.

(c) The American Society for Clinical Investigation, Inc. 0021-9738/88/03/0700/10 \$2.00

Volume 81, March 1988, 700-709 phospholipase C/diglyceride lipase (2-5), resulting in an increased availability of AA, the rate-limiting step for eicosanoid synthesis (6). However, under physiological conditions, the release of fatty acids after cell stimulation is followed by a subsequent increase in acyltransferase activities (7) that protect the membrane from accumulation of perturbing agents such as lysophospholipids and free fatty acids (FFA) (8-10).

Extensive work in the last few years implicates perturbations in AA metabolism leading to an increased production of eicosanoids as mediators of many types of shock and trauma, including ischemia (11), hemorrhagic shock (12), traumatic shock (13), endotoxic shock, and endotoxemia (14-18). This hypothesis is supported by the observed improvement in survival rate and reduced severity of organ infarction when inhibitors of cyclooxygenase and lipoxygenase (the two main pathways involved in the initiation of AA metabolism) are utilized $(11,13,15,19)$. In the present study we have examined the effect of chronic, nonlethal endotoxemia in the initial removal of $\left[1-{ }^{14} \mathrm{C}\right] \mathrm{AA}$ from the FFA pool which reflects its activation to AA-CoA and its subsequent esterification into glycerolipids through the AA-CoA:lysophospholipid acyltransferase-catalyzed enzymatic pathway. We have found that chronic endotoxemia greatly decreases the efficiency of hepatocytes to esterify AA into phospholipids. This impairment of AA esterification and the reported increase of phospholipase $A_{2}$ activity after Escherichia coli endotoxin (ET) administration (20-23) could contribute to a high availability of the precursor for eicosanoid synthesis. Moreover, the analysis of the fatty acid composition of phospholipids suggests that perturbations in AA metabolism could be involved, at least in part, in the observed decreased content of AA in phosphatidylinositol (PI), known to play a central role in membrane transsignaling processes.

\section{Methods}

Animal preparation. Male Sprague-Dawley rats weighing $350-400 \mathrm{~g}$ and maintained on a standard laboratory diet prior to surgery were used. Rats received one of four treatments: $(a)$ control-free access to food and water until the day of the experiment; $(b)$ pair-feeding - food intake was reduced to match that voluntarily eaten by endotoxin-infused rats; $(c$ and $d)$ "saline-pump" and "ET-pump"-continuous infusion i.v. with sterile isotonic saline and $0.1 \mathrm{mg}$ of ET/100 g body weight per $24 \mathrm{~h}$, respectively, at a rate of $10 \mu \mathrm{l} / \mathrm{h}$. Saline or ET (026: B6, Difco Laboratories, Inc., Detroit, MI) was delivered i.v. via subcutaneously implanted osmotic minipumps (Alzet 2ML 1, Alza Corporation, Palo Alto, CA) (24). The flow rate of the osmotic pumps was evaluated in vitro and was found to be linear for up to $6 \mathrm{~d}$. ET infusion began 42 $h$ after pump implantation, to allow for postsurgical recovery of the animals. During these $42 \mathrm{~h}$ sterile saline was infused. The rats were killed $30 \mathrm{~h}$ after the onset of ET infusion when they were in the morbid phase of the continuous endotoxemia (24). In previous studies we have measured the level of circulating endotoxin starting at $6 \mathrm{~h}$ and up to $5 \mathrm{~d}$ of continuous endotoxin infusion $(24,25)$. By $6 \mathrm{~h}$ of continuous infusion the average plasma endotoxin concentration was $0.96 \mu \mathrm{g} / \mathrm{ml}$ and 
'de novo" phospholipid Phospholipase $A_{2}$

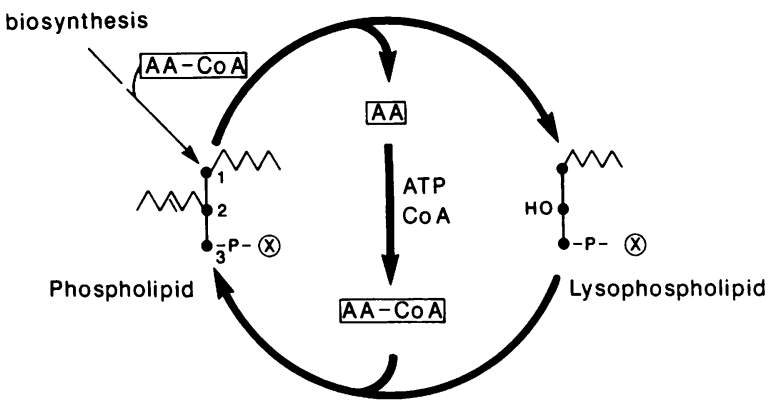

Acyltransferase

Figure 1. Schematic representation of the main enzymatic pathways involved in the esterification and turnover of arachidonic acid. Phospholipid structures are diagrammatically represented. The carbons of the glycerol molecule (๑) show the preferential esterification of a saturated fatty acid $(M)$ at the $C_{1}$ position, unsaturated ones ( $M$, i.e., $A A$ ) at the $C_{2}$ position, and a phosphate group (P) at the $C_{3}$ position. ( $\left.\otimes\right)$ A hydrogen for phosphatidic acid or base for other phospholipids, i.e., inositol for phosphatidylinositol; AA-CoA, arachidonoyl-coenzyme-A ester.

remained at comparable levels through $5 \mathrm{~d}$ of infusion. None of the plasma samples obtained at matched time points from saline-infused rats contained any detectable amount of endotoxin.

Hepatocyte isolation. Hepatocytes were isolated by a modification of the method of Berry and Friend (26) as previously described (27). Liver was perfused "in situ" with an oxygenated $\mathrm{Ca}^{2+}$-free buffer, followed by recycling the same buffer containing $\mathrm{CaCl}_{2}(2.5 \mathrm{mM})$ and collagenase (4,250 U, corresponding to $25 \mathrm{mg}$ of enzyme) for $13 \mathrm{~min}$. The cells were suspended at a concentration of $40 \mathrm{mg}$ wet $\mathrm{wt} / \mathrm{ml}$ in Krebs-Ringer bicarbonate medium. This buffer contains (mM): $\mathrm{NaCl}$, $120 ; \mathrm{KCl}, 5.0 ; \mathrm{CaCl}_{2}, 1.8 ; \mathrm{MgSO}_{4}, 1.2 ; \mathrm{KH}_{2} \mathrm{PO}_{4}, 1.2 ; \mathrm{NaHCO}_{3}, 25$; glucose, 11 at $\mathrm{pH}$ 7.45. Cell suspensions were maintained at room temperature with carbogen being continuously blown over the surface. The viability of the cells was higher than $90 \%$ (tryplan blue exclusion).

Isolation and analysis of the fatty acid profile of phospholipids. Aliquots of $2-\mathrm{ml}$ cell suspensions $(40 \mathrm{mg}$ wet $\mathrm{wt} / \mathrm{ml}$ ) were centrifuged at $1,000 \mathrm{~g}$ for $5 \mathrm{~min}$, the supernatant was discarded, and lipids were extracted from the pellet with chloroform/methanol 2:1 (by volume). The extracts were washed (28) and the phospholipids (PLs) were isolated by a two-dimensional thin-layer chromatographic system (TLC) according to Rouser et al. (29). Aliquots of the samples were spotted under nitrogen on precoated Silica gel $\mathrm{H}$ plates (Analtech, Inc., Newark, DE) $0.25 \mathrm{~mm}$ thick. The plates were developed in the first dimension using chloroform/methanol/ammonia, 13:5:1, by volume and then in the second dimension using chloroform/acetone/methanol/ acetic acid/water, 6:8:2:2:1, by volume. After completion of the TLC procedure, the plates were dried with an air gun, sprayed with $0.2 \%$ of $2^{\prime} 7$-dichlorofluorescein in methanol, and dried again under a nitrogen atmosphere. With UV light, the spots were visualized, scraped into tubes, and derivatized to methyl esters of fatty acids with $14 \% \mathrm{BF}_{3}$ in methanol (30). Fatty acid methyl esters were determined quantitatively by gas-liquid chromatography (GLC), using methyl nonadecanoate as internal standard. A gas chromatograph (model 790, Hewlett-Packard, Inc., Palo Alto, CA) equipped with flame ionization detector and a glass capillary column $(15 \mathrm{~m} \times 0.2-\mathrm{mm}$ inside diameter) packed with $10 \%$ SP 2330 on 100-200 Chromosorb WAW (Supelco, Inc., Bellefonte, PA), and helium carrier (flow rate $1 \mathrm{ml} / \mathrm{min}$ ) was used. The oven was programmed from $170^{\circ} \mathrm{C}$ to $220^{\circ} \mathrm{C}$ at $4^{\circ} \mathrm{C} / \mathrm{min}$. The peaks were identified on the basis of the retention time compared with the standards. To avoid peroxidation of unsaturated fatty acids, the solvents used for lipid extraction and TLC contained 2,6-di-tert-butyl-p-cresol $(50 \mathrm{mg} / \mathrm{liter})$ as an antioxidant and the extracts were stored under $\mathrm{N}_{2}$ at $-70^{\circ} \mathrm{C}$ until their use. Proteins were determined by the method of Lowry et al. (31) using bovine serum albumin as a standard.

Incorporation of $\left[{ }^{14} \mathrm{C}\right] \mathrm{AA}$ into glycerolipids. Aliquots of $0.5-\mathrm{ml}$ cell suspensions ( $40 \mathrm{mg}$ wet $\mathrm{wt} / \mathrm{ml}$ ) were transferred to plastic tubes and incubated in the presence of $\left[1-{ }^{14} \mathrm{C}\right] \mathrm{AA}$ as a sodium salt $(0.5 \mu \mathrm{Ci} / \mathrm{ml}$, sp act $58 \mathrm{mCi} / \mathrm{mmol}$ ) in a shaking water bath at $37^{\circ} \mathrm{C}$ for different periods of time up to $30 \mathrm{~min}$, under carbogen. The reaction was terminated by adding $7 \mathrm{ml}$ of chloroform/methanol 1:1 (by volume) containing 0.5 $\mathrm{mg}$ of cold AA/ $100 \mathrm{ml}$ as a carrier. After at least $2 \mathrm{~h}$ at room temperature, the extracts were centrifuged and the residue extracted once more with $3 \mathrm{ml}$ of chloroform/methanol 2:1 (by volume). The chloroform extracts were combined and washed according to the procedure of Folch et al. (28). Samples were dried under $\mathrm{N}_{2}$ and resuspended in a known amount of chloroform/methanol 2:1, and the tubes were kept under $\mathrm{N}_{2}$ at $-70^{\circ} \mathrm{C}$ until further analysis. Blanks ( 0 time) were prepared and processed as the rest of the samples to substract the nonspecific adsorption of $\left[1-{ }^{14} \mathrm{C}\right] \mathrm{AA}$ to individual lipids. Aliquots were spotted in duplicate on precoated Silica gel $\mathrm{H}$ plates and PLs isolated using the bidimensional chromatographic system of Rouser et al. (29) previously described. Phosphatidic acid (PA), phosphatidylserine (PS), and PI were added as carriers. From the same plate the FFA fraction was recovered, which ran with the solvent front of the second dimension at the level of phosphatidylethanolamine (PE). For separation of neutral lipids, aliquots in duplicate were applied to Silica gel gypsum hard layer plates and resolved by monodimensional TLC using chloroform/acetone, $96: 4$ by volume. This method provides a good resolution of diacylglycerol (DG) and triacylglycerol (TG) while FFA remained close to the origin, thus avoiding contamination of the DG pool by diffusion of the labeled fatty acids on the plate. The plates were developed in iodine, the spots were scraped into vials, and the silica gel was dispersed in $0.5 \mathrm{ml}$ of water. The possible quenching effect of the iodine was checked and no interference with regard to ${ }^{14} \mathrm{C}$-labeling was observed. Furthermore, the spots were scraped when iodine was already sublimated. The radioactivity was counted in a liquid scintillation counter, using $10 \mathrm{ml}$ of Ready Solv economy premixed (Beckman Instruments, Inc., Palo Alto, CA) as scintillation fluid.

Chemicals. All solvents used in these experiments were HPLCgrade and purchased from J. T. Baker Chemical Co. (Phillipsburg, NJ). Lipid standards and $14 \%$ boron trifluoride-methanol were purchased from Sigma Chemical Co. (St. Louis, MO). Precoated Silica gel H plates and Silica gel GHL plates were obtained from Analtech, Inc. $\left[1-{ }^{14} \mathrm{C}\right]$ arachidonic acid (sp act $58 \mathrm{mCi} / \mathrm{mmol}$ ) was purchased from Amersham Corp (Arlington Heights, IL). Collagenase (CLSII, containing $170 \mathrm{U} / \mathrm{mg}$ ) was obtained from Cooper Biomedical Inc. (Irvine, CA). Ready-Solv EP was purchased from Beckman Instruments Inc.

Statistical analysis. Results are presented as mean \pm SD from the number of samples specified in each case. Differences between two samples were analyzed by Student's $t$ test (32). Results were considered statistically significant when $P<0.05$.

\section{Results}

$\left[1-{ }^{14} \mathrm{C}\right] \mathrm{AA}$ metabolism in hepatocytes. Hepatocytes from control and pair-fed rats were incubated with $0.5 \mu \mathrm{Ci}\left[1-{ }^{14} \mathrm{C}\right] \mathrm{AA} /$ $\mathrm{ml}$ for up to $30 \mathrm{~min}$, and the incorporation of radiolabel into glycerolipids and the remaining precursor in the FFA pool were determined at various times as shown in Fig. 2. The removal of $\left[1-{ }^{14} \mathrm{C}\right] \mathrm{AA}$ is faster in cells from pair-fed than from control rats and in both cases shows a biphasic curve. By 3 min of incubation $34 \%$ in control cells and $46 \%$ in cells from pairfed animals is removed from the FFA fraction. After a lag period observed between 3 and 5 min of incubation for controls and between 2 and 3 min for pair-fed rats $\left[1-{ }^{14} \mathrm{C}\right] \mathrm{AA}$ continues to be utilized, and by 30 min only $5-6 \%$ of the added precursor remains unesterified in both groups. In control cells 


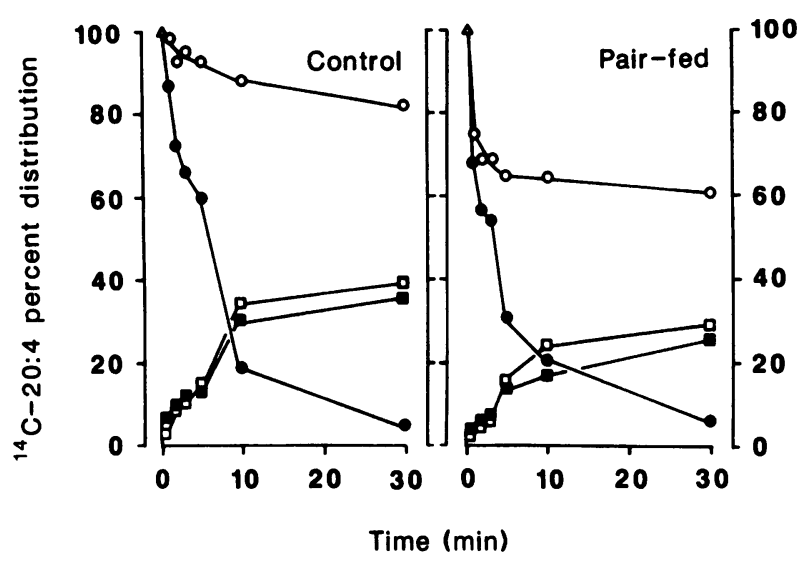

Figure 2. Effect of food restriction on the percent distribution of

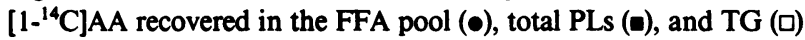
as a function of time. Hepatocytes $(40 \mathrm{mg}$ wet $\mathrm{wt} / \mathrm{ml}$ ) were incubated with $\left[1-{ }^{14} \mathrm{C}\right] \mathrm{AA}(0.5 \mu \mathrm{Ci} / \mathrm{ml}$; SA $58 \mathrm{Ci} / \mathrm{mmol})$ in Krebs-Ringer bicarbonate buffer at $37^{\circ} \mathrm{C}$ under carbogen. At the time points shown the incubation was terminated by extracting the lipids with chloroform:methanol 1:1. Neutral lipids and PLs were separated by TLC and the amount of ${ }^{14} \mathrm{C}$-radioactivity was determined. Values are the average of triplicates of a single experiment and representative of two additional experiments. Standard deviations are not drawn, because they are smaller than the plot sizes. (o) The percentage of the total radioactive precursor added $(\Delta)$ to the samples, not recovered in the lipid fractions analyzed at different times of incubation. Control: hepatocytes from ad libitum fed rats. Pair-fed: normal rats offered the amount of food that was voluntarily consumed by ET-infused animals.

the time-dependent slopes and the level of radioactive precursor incorporated into TG and total PLs are similar and reflect the early fast esterification of $\left[1-{ }^{14} \mathrm{C}\right] \mathrm{AA}$, followed by a lag period (3-5 $\mathrm{min}$ ) and an increased uptake up to $10 \mathrm{~min}$ when the labeling of both lipid pools levels off. In cells from pair-fed rats, the labeling of neutral lipids and PLs peaks between 2 and $3 \mathrm{~min}$ and then begins to plateau. By $30 \mathrm{~min}$ of incubation in control cells, $39 \%$ and $36 \%$ of the radioactivity is recovered in TG and the PL fraction, respectively, while in cells of pair-fed rats these values are $29 \%$ and $25 \%$. The radioactivity recovered in the organic extract (including neutral lipids, PLs, and FFA fractions) decreases progressively to $82 \%$ and $61 \%$ of the original value for cells from control and pair-fed animals, respectively, at $30 \mathrm{~min}$. This could reflect the utilization of AA in other metabolic pathways, i.e., its oxidation to $\mathrm{CO}_{2}$ and formation of ketone bodies. The labeling of individual lipids as a function of time is shown in Fig. 3. In control cells PA labeling peaks at $2 \mathrm{~min}$ and is followed by a peak in DG labeling at 3 min. From the first time analyzed $(1 \mathrm{~min})$, the labeling of individual glycerolipids is very active, especially TG which amounts to $\sim 30 \%$ and $50 \%$ of the total esterified AA at $1 \mathrm{~min}$ and $30 \mathrm{~min}$ of incubation, respectively (data not shown). In cells from pair-fed rats PA presents two peaks at 2 and $5 \mathrm{~min}$, possibly reflecting the accessibility of the precursor to different metabolic pools present in food-restricted animals. DG, on the other hand, peaks at $5 \mathrm{~min}$ reaching a value lower than the maximal observed for control cells. Thereafter, the labeling of both lipids decreases rapidly and at $30 \mathrm{~min}$ it is similar to that in control cells. The esterfication of AA both in TG and individual PLs is greatly reduced as compared with control cells. By 30 min, the labeling of PI and PE attains values $44 \%$ lower

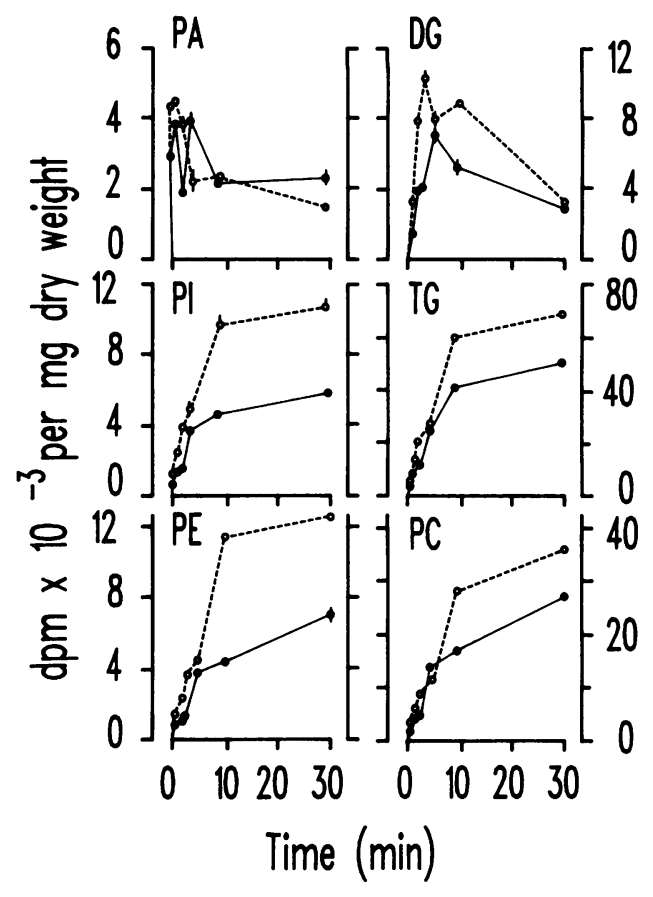

Figure 3. Labeling of individual lipids with $\left[1-{ }^{14} \mathrm{C}\right] \mathrm{AA}$ in isolated hepatocytes from control $(0)$ and food-restricted $(\bullet)$ rats. Other details as in Fig. 2.

than in control cells while those of TG and PC are reduced only by $26 \%$.

The differences in $\left[1-{ }^{14} \mathrm{C}\right] \mathrm{AA}$ removal and esterfication between saline and ET-infused rats are shown in Fig. 4. In cells from saline-infused rats, the decrease in the FFA pool labeling also shows two phases. The first one is very fast and by $3 \mathrm{~min}$ $60 \%$ of the labeled precursor has been removed from the unesterified fatty acid pool. Thereafter the removal of $\left[1-{ }^{14} \mathrm{C}\right] \mathrm{AA}$ occurs at a slow rate and by 30 min only $4 \%$ of the added precursor remains unesterified. The labeling of TG and PLs increases linearly with time up to $10 \mathrm{~min}$, when it levels off. Similarly to pair-fed rats, a significant proportion of the added precursor is not recovered in the lipid pools analyzed ( $28 \%$ and $39 \%$ at 3 and $30 \mathrm{~min}$, respectively).

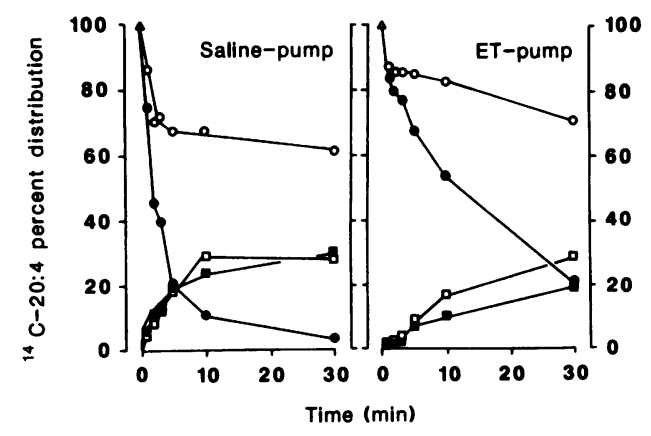

Figure 4. The effect of endotoxin infusion on the percent distribution of $\left[1-{ }^{14} \mathrm{C}\right] \mathrm{AA}$ as a function of time in isolated hepatocytes. Hepatocytes were isolated from rats infused i.v. for $30 \mathrm{~h}$ with saline (saline pump) or endotoxin (ET pump, $0.1 \mathrm{mg}$ ET/100 g body weight per $24 \mathrm{~h}$ ) via subcutaneously implanted osmotic minipumps. Values are the average of triplicates of a single experiment. Similar values were obtained in two other experiments. Other details as in Fig. 2. 
In ET-infused rats the most interesting observation is the decreased ability of the cells to metabolize $\left[1-{ }^{14} \mathrm{C}\right] \mathrm{AA}$. At 3 and $30 \mathrm{~min}$ of incubation only $23 \%$ and $79 \%$ of the $\left[1-{ }^{14} \mathrm{C}\right] \mathrm{AA}$ are removed from the FFA pool, concomitantly with its very slow esterification into lipids and also its lower utilization in other metabolic pathways (i.e., oxidation), which is reflected in a high recovery of the precursor in the lipid pools analyzed during incubation, as compared with saline-infused rats. Though at a slow rate, at $30 \mathrm{~min}$ of incubation TG attains labeling similar to saline-infused rats, while the labeling of individual PLs is greatly decreased (Fig. 5). PE attains the lowest labeling (55\% lower than in cells from saline-pump rats) and PI and PC labeling are decreased by $35 \%$ and $26 \%$, respectively. Interestingly, maximal labeling of the precursors in the de novo synthesis of lipids, PA and DG, is greatly decreased (six- and fourfold lower than in saline-pump rats, respectively). As in pair-fed rats, PA shows two peaks at 2 and 5 min while DG peaks at $5 \mathrm{~min}$.

The metabolic fate of $\left[1-{ }^{14} \mathrm{C}\right] \mathrm{AA}$ in hepatocytes is greatly altered as a consequence of food restriction and trauma induced by surgery and/or pump implantation per se as compared with control cells (Fig. 6). In both experimental conditions, the removal of the precursor from the FFA pool is faster than in control cells. However, its esterification into glycerolipids is greatly reduced, concomitantly with a higher shuttling of AA to other metabolic pathways. In ET-infused rats, the distribution of the precursor in the three fractions: unesterified, esterified, and utilized in other metabolic pathways, demonstrates a pattern similar to that observed in saline-pump rats, albeit with a sustained delay, (i.e., $30 \mathrm{~min}$ for ET pump rats as compared with $5 \mathrm{~min}$ for saline-pump rats). Thus, even though the labeled precursor is removed from the FFA pool at a slower rate in cells of ET-pump rats, than in saline-pump

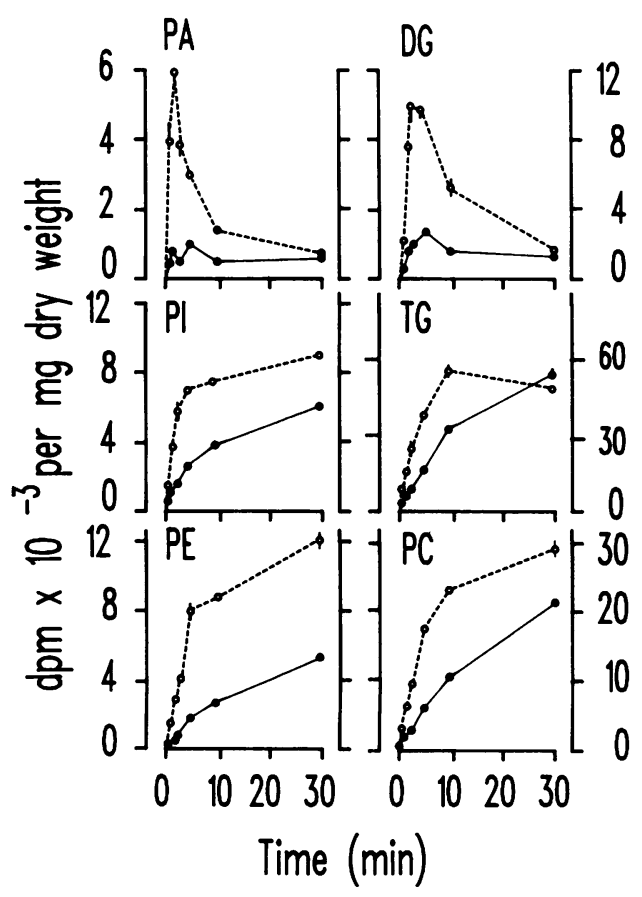

Figure 5. Time course of $\left[1-{ }^{14} \mathrm{C}\right] \mathrm{AA}$ incorporation into individual lipids of hepatocytes from saline- $(0)$ and ET-infused (๑) rats. Values are the average of triplicates $\pm \mathrm{SD}$ (shown when visible). Other details as in Figs. 3 and 4.

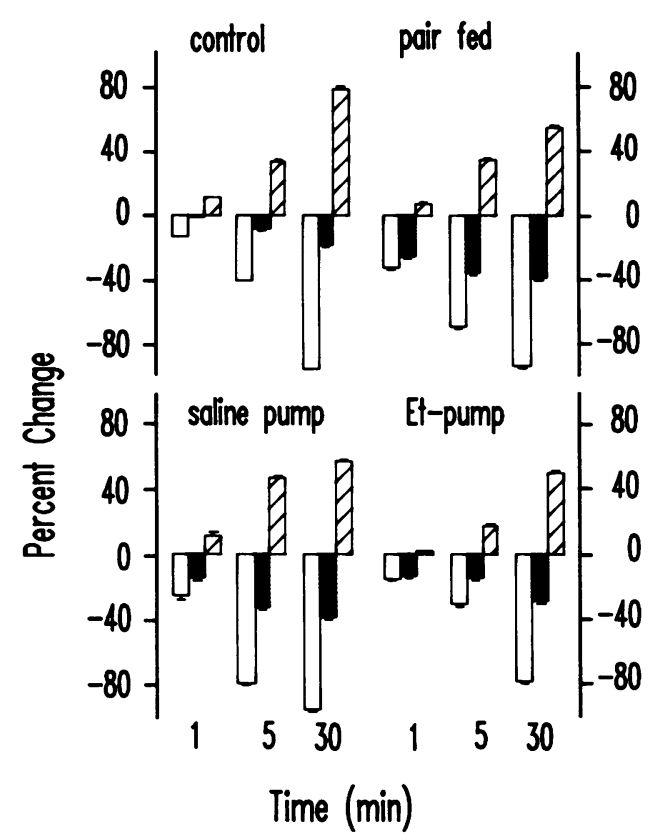

Figure 6. Comparative profile of $\left[1-{ }^{14} \mathrm{C}\right] \mathrm{AA}$ metabolism in hepatocytes from control, pair-fed, saline-, and ET-infused rats. Percent changes were calculated for 1,5 , and $30 \mathrm{~min}$ of incubation in the presence of $\left[1-{ }^{14} \mathrm{C}\right] \mathrm{AA}$. (Open bars) Unesterified $\left[1-{ }^{14} \mathrm{C}\right] \mathrm{AA}$; (hatched bars) $\left[1-{ }^{14} \mathrm{C}\right] \mathrm{AA}$ esterified in total glycerolipids; (solid bars) $\left[1-{ }^{14} \mathrm{C}\right] \mathrm{AA}$ not recovered in the abovementioned lipid pools.

rats, the proportions of AA esterified into glycerolipids and "metabolized" are similar in the two experimental groups. These observations were confirmed by further analysis of the data plotted in Figs. 1 and 3 (Table I). Values for the fractional AA disappearance are higher in pair-fed and saline cells as compared with control cells, while the lowest values for both AA disappearance and esterification were obtained with ET cells.

Fatty acid composition of PLs. The changes in fatty acid content and composition of individual PLs induced by food restriction or ET infusion was analyzed by GLC. The previously observed increase of sphingomyelin content in ETpump rats (55\% as compared with saline-pump rats) (33) occurs with no change in its fatty acids components (24:0, $28 \%$; $16: 0,20 \% ; 24: 1,14.5 \% ; 23: 0,12 \%)$. Food restriction results in a small decrease in PS content, while ET infusion increases this pool (Table II) in agreement with previous quantitation by phosphorus determinations from a larger number of samples (33). The decrease in the mass of PS in

Table I. Rate Constants for AA Esterification and Disappearance from the FFA Pool

\begin{tabular}{lcc}
\hline \multicolumn{1}{c}{ Condition } & Fractional esterification & Fractional disappearance \\
\hline Control & $0.149 \pm 0.024$ & $0.138 \pm 0.017$ \\
Pair-fed & $0.144 \pm 0.020$ & $0.202 \pm 0.034$ \\
Saline pump & $0.271 \pm 0.020$ & $0.317 \pm 0.029$ \\
ET pump & $0.063 \pm 0.006$ & $0.054 \pm 0.006$
\end{tabular}

The functions were fit using Newton's method of iterative approximations with a least squares criterion of best fit. 
Table II. PS Content and Acyl Group Composition in Hepatocytes from Control, Pair-fed, Saline-, and ET-infused Rats

\begin{tabular}{|c|c|c|c|c|c|c|}
\hline Fatty acid & Control (4) & Pair-fed (3) & & Saline pump (3) & ET pump (3) & \\
\hline & \multicolumn{2}{|c|}{ nmol/mg protein } & (\%) & \multicolumn{2}{|c|}{ nmol/mg protein } & (\%) \\
\hline $16: 0$ & $0.9 \pm 0.1$ & $0.7 \pm 0.2$ & NS & $1.2 \pm 0.1$ & $1.1 \pm 0.1$ & NS \\
\hline $18: 0$ & $8.2 \pm 0.6$ & $6.8 \pm 0.4^{*}$ & (83) & $8.0 \pm 1.3$ & $10.7 \pm 1.0^{\ddagger}$ & (134) \\
\hline $18: 1, \mathrm{n}-9$ & $0.3 \pm 0.0$ & $0.3 \pm 0.1$ & NS & $0.6 \pm 0.0$ & $1.1 \pm 0.0^{\ddagger}$ & (183) \\
\hline $18: 2, n-6$ & $0.3 \pm 0.0$ & $0.3 \pm 0.0$ & NS & $0.3 \pm 0.0$ & $0.4 \pm 0.0^{\ddagger}$ & (133) \\
\hline $20: 4, n-6$ & $3.8 \pm 0.1$ & $3.2 \pm 0.1^{*}$ & (84) & $3.4 \pm 0.0$ & $4.8 \pm 0.2^{\ddagger}$ & (141) \\
\hline $22: 5, n-3$ & $0.2 \pm 0.0$ & $0.1 \pm 0.0^{*}$ & (50) & $0.1 \pm 0.0$ & $0.1 \pm 0.0$ & NS \\
\hline $22: 6, n-3$ & $1.8 \pm 0.4$ & $1.5 \pm 0.0$ & NS & $1.5 \pm 0.0$ & $1.7 \pm 0.0^{\ddagger}$ & (113) \\
\hline Total PS & $7.7 \pm 0.4$ & $6.5 \pm 0.4^{*}$ & (84) & $7.5 \pm 0.5$ & $10.0 \pm 0.7^{\ddagger}$ & (133) \\
\hline Degree of unsaturation & 185.4 & 180.7 & & 159.0 & 160.3 & \\
\hline \multicolumn{7}{|l|}{ Molar ratio } \\
\hline $16: 0 / 18: 1$ & 3.0 & 2.3 & & 2.0 & 1.0 & \\
\hline $18: 0 / 20: 4$ & 2.2 & 2.1 & & 2.4 & 2.2 & \\
\hline
\end{tabular}

Values for individual fatty acids are expressed as mean \pm SD from the number of individual samples in parentheses. Total PS content was calculated by dividing the moles of total fatty acids in the samples by 2 . (\%), percentage with respect to control or saline-pump values. The degree of unsaturation is calculated as the sum of the products of the percentage of each unsaturated acyl group and its number of double bonds. The contribution of other minor fatty acids has not been included. Statistically significant differences $(P<0.05)$ between control and pair-fed $\left(^{*}\right)$ and between saline and ET-pump $\left(^{\ddagger}\right)$. NS, values not statistically significantly different from their respective controls. Other details as in Figs. 1 and 3.

pair-fed as compared with control cells is mainly accounted for by the lower content of 18:0. In cells from ET-pump rats, 18:0, $20: 4_{n-6}, 18: 1$ and $18: 2_{n-6}$ contribute to the observed increase in PS. As previously observed for TG (33) and in all the PLs analyzed in the present study, the content of $22: 5_{n-3}$ is lower in all experimental conditions as compared with control cells. Possibly this reflects its desaturation to preserve, under different stress conditions, the endogenous content of $22: 6_{n-3}$ esterified into lipids. The effects of food restriction and ET infusion on rat hepatocyte PI are shown in Table III. In pair-fed rats, the total content of PI is decreased by $20 \%$. This decrease affects all PI-acyl groups and to a low extent 18:0 and 20:4 $n$.
ET infusion results in decreased content of $20: 3_{n-6}$ and $20: 4_{n-6}$ $(P<0.025$ and $P<0.05$, respectively) as compared with saline-pump rats while the total PI content is the same. Both the ratio 18:0/20:4 (1.1) and the degree of unsaturation are maintained in all groups, except ET-pump rats, in which the first is increased to 1.4 and the second is decreased as compared with saline-pump rats. Food restriction results in a decrease in the content of PE (25\%) as compared with control cells, (Table IV). As shown for PI, 20:4n-6 and 18:0 are the acyl-groups less affected. Interestingly ET-infusion increases the degree of unsaturation in PE due to a small but significantly increased content of $22: 6_{\mathrm{n}-3}(P<0.01)$ and $22: 5_{\mathrm{n}-3}(P<0.005)$ concomi-

Table III. Changes Induced by Food Restriction and In Vivo Endotoxin Infusion in PI Content and Fatty Acid Composition

\begin{tabular}{|c|c|c|c|c|c|c|}
\hline Fatty acid & Control (6) & Pair-fed (3) & & Saline pump (4) & ET pump (6) & \\
\hline & \multicolumn{2}{|c|}{ nmol/mg protein } & (\%) & \multicolumn{2}{|c|}{ nmol/mg protein } & (\%) \\
\hline $16: 0$ & $3.2 \pm 0.6$ & $1.2 \pm 0.3^{*}$ & (38) & $2.4 \pm 0.2$ & $2.2 \pm 0.5$ & NS \\
\hline $18: 0$ & $21.0 \pm 1.4$ & $18.8 \pm 3.4$ & NS & $20.5 \pm 1.5$ & $19.4 \pm 2.7$ & NS \\
\hline $18: 1, \mathrm{n}-9$ & $0.6 \pm 0.2$ & $0.3 \pm 0.1^{*}$ & $(50)$ & $0.5 \pm 0.0$ & $0.6 \pm 0.1$ & NS \\
\hline $18: 2, n-6$ & $1.2 \pm 0.2$ & $0.4 \pm 0.1^{*}$ & (33) & $1.1 \pm 0.2$ & $1.3 \pm 0.1$ & NS \\
\hline $20: 3, n-6$ & $1.2 \pm 0.2$ & $0.2 \pm 0.1^{*}$ & (17) & $0.8 \pm 0.2$ & $0.4 \pm 0.2^{\ddagger}$ & (50) \\
\hline $20: 4, n-6$ & $19.2 \pm 1.8$ & $17.1 \pm 1.2$ & NS & $18.0 \pm 2.4$ & $14.4 \pm 1.8^{\ddagger}$ & (80) \\
\hline $22: 5, n-3$ & $0.6 \pm 0.0$ & $0.3 \pm 0.1^{*}$ & (50) & $0.4 \pm 0.2$ & $0.3 \pm 0.1$ & NS \\
\hline $22: 6, n-3$ & $0.8 \pm 0.2$ & $0 . \dot{4} \pm 0.1^{*}$ & (50) & $0.8 \pm 0.2$ & $0.9 \pm 0.2$ & NS \\
\hline Total PI & $23.8 \pm 2.0$ & $18.8 \pm 2.4^{*}$ & (79) & $22.1 \pm 2.1$ & $19.9 \pm 3.0$ & NS \\
\hline Degree of unsaturation & 190.2 & 190.6 & & 187.2 & 174.9 & \\
\hline \multicolumn{7}{|l|}{ Molar ratio } \\
\hline $16: 0 / 18: 1$ & 5.4 & 4.0 & & 4.8 & 3.7 & \\
\hline $18: 0 / 20: 4$ & 1.1 & 1.1 & & 1.1 & 1.4 & \\
\hline
\end{tabular}

Details as in Figs. 1 and 3 and Table I. Statistically significant differences $(P<0.05)$ between control and pair-fed $\left(^{*}\right)$ and between saline and ET pump $\left(^{\ddagger}\right)$. NS, values not statistically significantly different from their respective controls. 
Table IV. PE Content and Acyl Group Composition in Hepatocytes from Control, Pair-fed, Saline-, and ET-infused Rats

\begin{tabular}{|c|c|c|c|c|c|c|}
\hline Fatty acid & Control (5) & Pair-fed (3) & & Saline pump (5) & ET pump (6) & \\
\hline & \multicolumn{2}{|c|}{ nmol/mg protein } & (\%) & \multicolumn{2}{|c|}{ nmol/mg protein } & (\%) \\
\hline $16: 0$ & $30.8 \pm 2.4$ & $18.4 \pm 2.8^{*}$ & (60) & $28.6 \pm 2.0$ & $24.2 \pm 2.8^{\ddagger}$ & (85) \\
\hline $18: 0$ & $39.8 \pm 3.4$ & $33.4 \pm 2.6^{*}$ & (84) & $42.8 \pm 3.4$ & $42.6 \pm 3.2$ & NS \\
\hline $18: 1, n-9$ & $5.4 \pm 0.8$ & $4.6 \pm 2.0$ & NS & $4.6 \pm 0.6$ & $4.4 \pm 1.0$ & NS \\
\hline $18: 2, n-6$ & $15.2 \pm 1.0$ & $10.8 \pm 2.2^{*}$ & (71) & $13.0 \pm 1.4$ & $13.0 \pm 1.2$ & NS \\
\hline $20: 4, n-6$ & $36.4 \pm 3.2$ & $29.8 \pm 3.8^{*}$ & (82) & $35.4 \pm 4.2$ & $33.8 \pm 3.0$ & NS \\
\hline $22: 5, \mathrm{n}-3$ & $3.6 \pm 0.2$ & $1.3 \pm 0.2^{*}$ & (36) & $1.6 \pm 0.4$ & $2.6 \pm 0.4^{\ddagger}$ & (163) \\
\hline $22: 6, n-3$ & $12.8 \pm 1.6$ & $9.6 \pm 1.8^{*}$ & (75) & $14.4 \pm 1.2$ & $16.8 \pm 1.2^{\ddagger}$ & (117) \\
\hline Total PE & $71.9 \pm 4.7$ & $53.8 \pm 6.7^{*}$ & (75) & $70.4 \pm 3.1$ & $68.2 \pm 4.3$ & NS \\
\hline Degree of unsaturation & 192.1 & 183.7 & & 192.1 & 202.6 & \\
\hline \multicolumn{7}{|l|}{ Molar ratio } \\
\hline $16: 0 / 18: 1$ & 5.7 & 4.0 & & 6.2 & 5.5 & \\
\hline $18: 0 / 20: 4$ & 1.1 & 1.1 & & 1.2 & 1.3 & \\
\hline
\end{tabular}

Details as in Table I. Statistically significant differences $(P<0.05)$ between control and pair-fed $\left({ }^{*}\right)$ and between saline and ET pump $\left({ }^{\ddagger}\right)$. NS, values not statistically significantly different from their respective controls.

tantly with a reduction in 16:0 $(P<0.025)$ in comparison with saline-pump rats. The observed decrease in PC content (23\%) in pair-fed animals occurs with a significant decrease in all its acyl groups, 18:0 and 20:4 $4_{n-6}$ showing the lowest percent changes. (Table V). In ET-pump rats, the content of PC remains unchanged with respect to saline-pump rats, and as observed for PE, the content of $22: 6_{\mathrm{n}-6}$ is significantly increased $(P<0.05)$.

\section{Discussion}

The results presented in this article demonstrate that, as a consequence of continuous in vivo ET infusion, the efficiency of hepatocytes to activate/acylate $\left[1-{ }^{14} \mathrm{C}\right] \mathrm{AA}$ is greatly decreased with consequent accumulation of the labeled precursor in the unesterified pool and its slow esterification into PLS.
Moreover, analysis of their fatty acid composition shows a small, but significant reduction in the content of AA only in PI.

Arachidonate is stored in the cells esterified into PLs and its active turnover, mediated by the coupled activities of phospholipase/acyltransferase, is regulated in such a way as to maintain a very low level of free AA (2). The analysis of AA content of individual glycerolipids in hepatocytes reveals that $49 \%$ of the total AA is esterified into PC, $30 \%$ into PE, and $16 \%$ into PI. The remaining 5\% is esterified in other minor PLs and TG $(2 \%)$ while only $\sim 0.2-0.3 \%$ of the total is found unesterified. Fluctuations in the level of free AA between cell preparations and with different collagenases used for liver perfusion (unpublished observation) suggest that $\mathrm{AA}$ as well as other fatty acids are artifactually released during cell isolation. This fact renders uncertain the determination of possible differ-

Table V. PC Content and Fatty Acid Composition in Hepatocytes from Control, Pair-fed, Saline-, and Endotoxin-infused Rats

\begin{tabular}{|c|c|c|c|c|c|c|}
\hline Fatty acid & Control (6) & Pair-fed (4) & & Saline pump (6 & ET pump (6) & \\
\hline & \multicolumn{2}{|c|}{ nmol/mg protein } & (\%) & \multicolumn{2}{|c|}{ nmol/mg protein } & (\%) \\
\hline $16: 0$ & $60.0 \pm 4.4$ & $45.0 \pm 3.6^{*}$ & (75) & $60.6 \pm 2.0$ & $64.4 \pm 2.2^{\ddagger}$ & (107) \\
\hline $18: 0$ & $72.4 \pm 2.8$ & $64.4 \pm 5.4^{*}$ & (89) & $76.0 \pm 6.2$ & $73.2 \pm 2.8$ & NS \\
\hline $18: 1, n-9$ & $17.4 \pm 3.6$ & $11.6 \pm 3.8^{*}$ & (67) & $18.4 \pm 2.6$ & $19.6 \pm 2.0$ & NS \\
\hline $18: 2, n-6$ & $50.6 \pm 2.4$ & $33.4 \pm 2.6^{*}$ & $(66)$ & $47.6 \pm 2.2$ & $48.0 \pm 2.4$ & NS \\
\hline $20: 4, n-6$ & $59.0 \pm 2.8$ & $52.4 \pm 5.0^{*}$ & (89) & $62.6 \pm 6.0$ & $60.4 \pm 5.0$ & NS \\
\hline $22: 5, \mathrm{n}-3$ & $3.0 \pm 0.4$ & $1.0 \pm 0.2^{*}$ & (33) & $1.4 \pm 0.2$ & $1.6 \pm 0.6$ & NS \\
\hline $22: 6, n-3$ & $15.2 \pm 1.8$ & $9.6 \pm 1.6^{*}$ & (63) & $11.4 \pm 1.6$ & $13.2 \pm 0.8^{\ddagger}$ & (116) \\
\hline Total PC & $141.0 \pm 6.6$ & $108.5 \pm 3.5^{*}$ & (77) & $139.2 \pm 5.8$ & $140.0 \pm 1.3$ & NS \\
\hline $\begin{array}{l}\text { Degree of unsaturation } \\
\text { Molar ratio }\end{array}$ & 163.3 & 161.6 & & 158.0 & 159.0 & \\
\hline \multicolumn{7}{|l|}{ Molar ratio } \\
\hline $16: 0 / 18: 1$ & 3.4 & 3.9 & & 3.3 & 3.3 & \\
\hline $18: 0 / 20: 4$ & 1.2 & 1.2 & & 1.2 & 1.2 & \\
\hline
\end{tabular}

Details as in Table I. Statistically significant differences $(P<0.05)$ between control and pair-fed $\left(^{*}\right)$ and between saline and ET pump $\left(^{\ddagger}\right)$. NS, values not statistically significantly different from their respective controls. 
ences in endogenous free AA content between different experimental conditions. Therefore, the resting levels of free AA in the intact tissue must be only traces as previously reported for various cells and tissues $(2,5,34)$.

The potential fate of free AA includes being used as a precursor for eicosanoid synthesis and activation prior to oxidation or esterification into glycerolipids, as illustrated below:

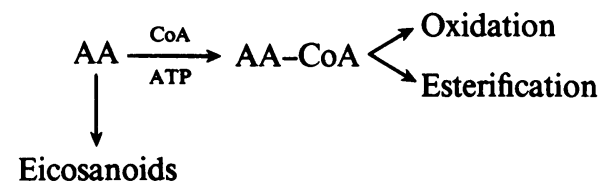

Although liver microsomes have the synthetic capacity to oxidize AA (35-38) their ability is very low as compared with other tissues $(37,38)$. The efficient activation/acylation of $\left[1-{ }^{14} \mathrm{C}\right] \mathrm{AA}$ and the relatively high endogenous content of AA in isolated hepatocytes, $0.17 \mathrm{nmol}$ per $\mathrm{mg}$ dry weight (manuscript submitted for publication), will decrease the probability of $\left[1-{ }^{14} \mathrm{C}\right] \mathrm{AA}$ being diverted to eicosanoid synthesis. Thus, the decreased labeling of the FFA pool as a function of time will mainly reflect the activation of $\left[1-{ }^{14} \mathrm{C}\right] \mathrm{AA}$ to $\left[1-{ }^{14} \mathrm{C}\right] \mathrm{AA}-\mathrm{CoA}$. This pathway is catalyzed by an acyl-CoA synthetase present in hepatocyte microsomes (39-41) as well as in mitochondria $(40,42)$. In addition, the presence of a specific AA-CoA synthetase widely distributed among various tissues (42-45) has been recently reported. Although in low concentration, it is also present in the liver (45) and could contribute to the efficient uptake of AA from the earliest time of incubation, contributing to the observed biphasic kinetics curves in the four experimental conditions analyzed. In the brain, where a specific AA-CoA synthetase has been described (44), the metabolism of $\left[1-{ }^{14} \mathrm{C}\right] \mathrm{AA}$ also shows a similar biphasic curve, not observed for a saturated fatty acid (i.e., palmitic acid) (46). However, the accessibility of $\left[1-{ }^{14} \mathrm{C}\right] \mathrm{AA}$ to different metabolic pools and/or subcellular levels where its activation to AA-CoA occurs must also be considered.

The activated fatty acids (i.e., AA-CoA) can be either esterified into lipids or transferred to carnitine, which in turn facilitates the transport of fatty acids into mitochondria to oxidative pathways (47). A common observation related to $\left[1-{ }^{14} \mathrm{C}\right] \mathrm{AA}$ metabolism in hepatocytes is the significant proportion of the added precursor not recovered in the lipid pools analyzed. This may reflect the oxidative capacity of the cells when arachidonate is the substrate, a possibility that, in fact, was confirmed in ongoing studies in our laboratory (unpublished observation). It is well known that the partitioning of fatty acid-CoA esters between $\beta$-oxidation and esterification into glycerolipids is regulated by different stress hormones, e.g., glucagon, epinephine, glucocorticoids (47-49), and is shifted toward oxidative pathways during fasting with consequent increase in ketonemia $(48,49)$. Hence, a higher diversion of AA-CoA in cells from both pair-fed and saline-pump rats towards oxidative pathways (e.g., $\mathrm{CO}_{2}$ and ketone body production) will result in the observed decreased availability of the precursor for esterification into TG and PLs. Although we have not measured plasma ketone levels in these animals, it is well known that during fasting and stress conditions ketone bodies are increased in the plasma $(42,44)$. It is not known at present whether the pattern of $\left[{ }^{14} \mathrm{C}\right] \mathrm{AA}$ metabolism is a feature shared by all fatty acids, mainly saturated and monoenoic ones, that would be the main contributors to ketone body production.

In ET-infused rats on the other hand, AA metabolism is altered in a different way, suggesting that ET-infusion and not the nutritional state of the animal and/or surgical trauma is the primary factor involved. The slow removal of AA from the FFA pool in cells from ET-infused rats suggests that its metabolism is altered at an early step, previous to the branch point between oxidation and esterification, i.e., its activation to AACoA. Interestingly, no accumulation of ketone bodies in the plasma has been observed during endotoxicosis and sepsis ( 50 , 51), despite the fact that food consumption in sick animals is minimal and glucagon levels are greatly increased $(25,52)$. Hence the observed decrease in the ketogenic capacity of the liver cells could to some extent be due to the following: (a) A decreased efficiency in the activation of fatty acids-whether the observation for AA metabolism applies also for other saturated and monoenoic fatty acids (which are the main energetic sources) remains to be determined. (b) An efficient conversion of lactate, known to be increased in plasma during endotoxemia $(24,51,52)$ to malonyl-CoA-malonyl-CoA is a potent inhibitor and a key metabolite involved in the regulation of carnitine-acyltransferase activity (47). In fact, lactate has been shown to reduce the oxidation of unsaturated fatty acids in isolated hepatocytes favoring their esterification into lipids (53). However, although the proportion of AA possibly diverted to oxidative pathways in cells from ET-infused rats is lower than in those from saline-pump or pair-fed rats, this was not paralleled by a higher esterification into lipids, but by an accumulation of the precursor in the unesterified pool.

Different possibilities must be considered as the triggering factor in the observed decreased efficiency of liver cells to remove AA from the FFA pool:

Greater dilution of the precursor with endogenous $A A$. This possibility is unlikely, because no differences in the total free AA content between cells from saline and ET-infused rats have been observed as previously discussed.

Impaired accessibility of $A A$ to the activating enzymes. The influx of FFAs in hepatocytes depends on an efficient membrane transport. The presence of a membrane-associated carrier-mediated process has been suggested for palmitic acid (54) and for oleic acid (55) influx into hepatocytes. The transport of long-chain fatty acids from the plasma membrane through the aqueous environment of the cytosol to intracellular organelles, e.g., microsomes and mitochondria, is mediated by a fatty acid-binding protein (FABP) described in the liver and other tissues by Ockner and collaborators 15 years ago (56). This protein not only plays a carrier function similar to that of albumin in the systemic circulation (57), but experimental evidence also suggests that it is involved in the regulation of uptake (58), esterification (59), and $\beta$-oxidation (60) of fatty acids. Hence, the possibility that some of these carrier components implicated in the uptake and utilization of AA by the liver are altered in cells from ET-infused rats is an attractive hypothesis that we are considering at present.

Perturbation at the level of the ATP-dependent activation of $A A$ (i.e., acyl-CoA synthetase and/or arachidonoyl-CoA synthetase). The endogenous content of ATP-ADP-AMP in cells from saline and ET-infused rats was determined in our laboratory and no differences were observed (61). Although it is not clear at present which of these pathways is altered as a conse- 
quence of ET-infusion, the final result is decreased efficiency of those metabolic pathways in which AA-CoA is required.

It has been suggested that AA is more efficiently incorporated into PLs by the retailoring cycle involving lysophospholipid intermediates $(1,2)$. Hence, the observed very low labeling of the precursors in the de novo synthesis of glycerolipids: PA and DG, could have a minimal impact in tetraenoic lipid species synthesis. However, Holub (62) has suggested that in the liver the synthesis of arachidonoyl-PI involves both the de novo pathway and the turnover cycle to a similar extent. Of greater interest is the observation that PI, known for its high metabolic activity, is the only PL which shows a low content of AA in cells from ET-infused rats. This could be the combined result of the previously observed stimulated de novo synthesis (33) and a reduced esterification of $\left[1-{ }^{14} \mathrm{C}\right] \mathrm{AA}$ (present results). In pair-fed rats on the other hand, both the esterification of $\left[1-{ }^{14} \mathrm{C}\right] \mathrm{AA}$ into PI and its de novo synthesis (33) are greatly reduced concomitantly with a significant decrease in its endogenous content. Moreover, the observation that the decrease in PI affects all acyl groups to a greater extent than 18:0 and 20:4 suggests a selective preservation of tetraenoic species in liver cells, a common observation for virtually all the glycerolipids analyzed.

The very high labeling of TG $(50-60 \%$ of the total $\left[1-{ }^{14} \mathrm{C}\right] \mathrm{AA}$ esterified into glycerolipids) is a common occurrence in $\left[1-{ }^{14} \mathrm{C}\right] \mathrm{AA}$ metabolism in hepatocytes, which contrasts with the low content of AA in TG (2\% of the total AA esterified into glycerolipids) (33). This suggests that AA-TG is a very small, but metabolically very active pool. Moreover, as previously suggested for endothelial cells (63), AA-TG could serve not only as a reservoir of AA in hepatocytes, but also as an active donor of AA to be used in the retailoring of their membrane PLs.

An impairment in the AA activating/acylating enzymatic pathways during chronic endotoxemia could directly affect the dynamic equilibrum of AA-PL turnover regulated by the coordinated activities of phospholipase/acyltransferase, with several potential consequences: $(a)$ increased availability of free AA that could be used for eicosanoid synthesis; $(b)$ higher accumulation of FFA and lysophospholipids in some membrane domains where those lipid pools of highest turnover are localized-these degradative products are known for their detergent and perturbing properties at the membrane level $(8-10)$ and also for their stimulatory effects on some membranous enzymes $(9,10,64-66)$; (c) increased membrane permeability to ions-stimulation of phospholipase $A_{2}(67)$ as well as inhibition of acyl-transferase (68) have been involved in increased permeability to $\mathrm{Ca}^{2+} ;(d)$ perturbation in the microenvironment of some active membraneous proteins, i.e., receptors. An increased activity of phospholipase $A_{2}$ and/or a decreased activity of acyltransferase have been involved as the triggering factor of receptor down regulation $(5,22,69-72)$. In fact, a decreased number of vasopressin $\left(V_{1}\right)$ as well as $\alpha_{1-}$ adrenergic receptors has been reported in hepatocytes from chronically endotoxemic rats (73).

Recent evidence suggests that sepsis-related abnormalities in cellular biochemistry, especially involving receptors whose activation is coupled to changes in membrane inositol PL metabolism, are central to the problem of septic shock. Downregulation of hepatic $\alpha_{1}$-adrenergic receptors was described in rat models of acute and chronic septic shock, along with diminished adrenergic support of the vasculature $(74,75)$. Altered adrenergic activity was also noted in microvascular responses to ET administration (76).

In our own work we have demonstrated downregulation of hepatic vasopressin and $\alpha_{1}$-adrenergic receptors after chronic infusion of a nonlethal dose of ET (73), concurrently with alterations in phosphoinositide hydrolysis (77), $\mathrm{Ca}^{2+}$ metabolism (78), and phosphorylase $a$ activation (79) stimulated by agonist binding to these receptors. Furthermore, we also recently reported that continuous intravenous infusion of phorbol myristate acetate for $30 \mathrm{~h}$ via an implanted osmotic pump resulted in similar impairment of vasopressin-associated phosphoinositide metabolism as observed due to ET infusion (80). These findings are consistent with the hypothesis that $\alpha_{1}$ adrenergic as well as other agonists which function via $D G$ as a second messenger may act in a manner similar to phorbol esters in regulating receptor responsiveness through phosphorylation mechanisms $(81,82)$. Thus evidence from our work as well as from other investigators implicates adrenergic receptor dysfunction as an underlying cause of some metabolic and vascular problems associated with sepsis.

In addition, the new picture emerging from the present studies suggests that impairments in AA metabolism may constitute one of the sites of metabolic lesions underlying the hepatic functional perturbations observed during chronic endotoxemia.

\section{Acknowledgments}

We are indebted to Dr. Richard Odessey of the Department of Physiology, LSU Medical Center, New Orleans for performing the statistical analysis for the various rate constants. The skilled technical assistance of Jean Carnal, Karen DuSapin, Peter O'Malley, and Curtis Vande Stouwe is gratefully acknowledged.

This work was supported by National Institutes of Health grants GM-32654 and GM-30312.

\section{References}

1. Hill, E. E., and W. E. M. Lands. 1968. Incorporation of longchain and polyunsaturated acids into phosphatidate and phosphatidylcholine. Biochim. Biophys. Acta. 152:645-648.

2. Irvine, R. F. 1982. How is the level of free arachidonic acid controlled in mammalian cells? Biochem. J. 204:3-16.

3. Van Den Bosch, H. 1980. Intracellular phospholipase A. Biochim. Biophys. Acta. 604:191-246.

4. Billah, M. M., and E. G. Lapetina. 1982. Formation of lysophosphatidylinositol in platelets stimulated with thrombin or ionophore A 23187. J. Biol. Chem. 257:5196-5200.

5. Rodriguez de Turco, E. B. 1986. Drugs affecting membrane lipid catabolism: the brain free fatty acid effect. In Phospholipid Research and the Nervous System. Biochemical and Molecular Pharmacology. L. A. Horrocks, L. Freysz, and G. Toffano, editors. Fidia Research Series, Liviana Press, Padua, Italy. 57-66.

6. Flower, R. J., and G. J. Blackwell. 1976. The importance of phospholipase $\mathrm{A}_{2}$ in prostaglandin biosynthesis. Biochem. Pharmacol. 25:285-291.

7. Schrey, M. P., and R. P. Rubin. 1979. Characterization of a calcium-mediated activation of arachidonic acid turnover in adrenal phospholipids by corticotropin. J. Biol. Chem. 254:11234-11241.

8. Weltzien, H. V. 1979. Cytosolic and membrane-perturbing properties of lysophosphatidylcholine. Biochim. Biophys. Acta. 559:259-287.

9. Swoboda, G., J. Fritzsche, and W. Hasselbach. 1979. Effects of phospholipase $\mathrm{A}_{2}$ and albumin on the calcium-dependent ATPase and 
the lipid composition of sarcoplasmic membranes. Eur. J. Biochem. 95:77-88.

10. Baba, A., T. Tatsuno, and H. Iwata. 1984. Modulation by unsaturated fatty acids of norepinephrine- and adenosine-induced formation of cyclic AMP in brain slices. J. Neurochem. 42:192-197.

11. Lepran, I., and A. M. Lefer. 1985. Protective actions of propyl gallate, a lipoxygenase inhibitor, on the ischemic myocardium. Circ. Shock. 15:79-88.

12. Blasingham, M. C., and E. E. Selkurt. 1985. Role of the lung in metabolism of prostaglandin $\mathrm{E}$ during severe hemorhagic shock in the dog. Circ. Shock. 15:175-184.

13. Fletcher, J. R., and R. W. Ramwell. 1980. The role of prostaglandin systhetase inhibitors in shock and trauma. In Prostaglandin Synthetase Inhibitors: New Clinical Application. P. Ramwell, editor. Alan R. Liss, Inc., New York. 257-266.

14. Rietschel, E. T., U. Schade, O. Luederitz, H. Fischer, and B. A. Peskar. 1980. Prostaglandins in endotoxicosis. In Microbiology: 80. D Shlessinger, editor. American Society for Microbiology, Washington, D.C. 66-72.

15. Cook, J. A., W. C. Wise, and P. V. Halushka. 1980. Elevated thromboxane levels in the rat during endotoxic shock: protective effects of imidazole, 13-aza prostanoic acid or essential fatty acid deficiency. J. Clin. Invest. 65:227-230.

16. Bottoms, G. D., M. A. Johnson, C. H. Lamar, J. F. Fessler, and J. J. Turek. 1985. Endotoxin-induced eicosanoids production by equine vascular endothelial cells and neutrophils. Circ. Shock. 15:155-162.

17. Casey, L. C., T. R. Fletcher, M. I. Zmudka, and P. W. Ramwell. 1985. The role of thromboxane in primate endotoxin shock. J. Surg. Res. 39:140-149.

18. Cook, J. A., W. C. Wise, G. E. Tempel, and P. V. Halushka. 1985. Exchange transfusions in rats with a perfluorated blood substitute: effect on thromboxane $B_{2}$ levels during endotoxemia. Circ. Shock. 15:193-204.

19. Toth, P. D., S. A. Hamburger, G. H. Hastings, and W. V. Judy 1985. Benoxaprofen attenuation of lethal canine endotoxemic shock. Circ. Shock. 15:89-103.

20. Conde C., P. G. Barreno, A. M. Municio, and A. Suarez. 1981 In vitro and in vivo effect of Escherichia coli endotoxin on mitochondrial phospholipase $A_{2}$ activity. FEBS (Fed. Eur. Biochem. Soc.) Lett. 127:115-120.

21. Liu, M. S., and H. Takeda. 1982. Endotoxin-induced stimulation on phospholipase A activities in dog hearts. Biochem. Med. 28:62-69.

22. Liu, M. S., S. Ghosh, and G. F. Kang. 1983. Mechanism of endotoxin-induced reduction in the number of $\beta$-adrenergic receptors in dog livers: role of phospholipase A. Biochem. Med. 30:295-304.

23. Shakir, K. M. M., J. T. O’Brian, and S. L. Gartner. 1985. Enhanced phospholipase $A_{2}$ activity in rat plasma, liver, and intestinal mucosa following endotoxin treatment: a possible explanation for the protective effect of indomethacin in endotoxic shock. Metab. Clin. Exp. 34:176-182.

24. Fish, R. E., and J. A. Spitzer. 1984. Continuous infusion of endotoxin from an osmotic pump in the conscious unrestrained rat: a unique model of chronic endotoxemia. Circ. Shock. 12:135-149.

25. Spitzer, J. A., H. Friedman, C. Newton, R. Widen, S. Pros, and T. W. Klein. 1987. Suppressed in vitro blastogenic responsiveness of rat spleen cells after continuous infusion of endotoxin by an implanted osmotic pump. Proc. Soc. Exp. Biol. Med. 186:21-26.

26. Berry, M. N., and D. S. Friend. 1969. High-yield preparation of isolated rat liver parenchymal cells. J. Cell Biol. 43:506-520.

27. Deaciuc, I. V., and J. A. Spitzer. 1986. Effect of endotoxicosis and sepsis on intracellular calcium homeostasis in rat liver. Am. J. Physiol. 251:R984-R995.

28. Folch, J., M. Lees, and G. H. Sloane Stanley. 1957. A simple method for the isolation and purification of total lipids from animal tissues. J. Biol. Chem. 226:497-509.

29. Rouser, G., S. Fleischer, and A. Yamamoto. 1970. Two di- mensional thin layer chromatographic separation of polar lipids and determination of phospholipids by phosphorus analysis of spots. Lipids. 5:494-496.

30. Morrison, W. R., and L. M. Smith. 1964. Preparation of fatty acid methyl esters and dimethylacetals from lipids with boron fluoride-methanol. J. Lipid. Res. 5:600-608.

31. Lowry, O. H., N. J. Rosenbrough, A. L. Farr, and R. S. Randall. 1951. Protein measurement with the folin phenol reagent. J. Biol. Chem. 193:265-275.

32. Siegel, S. 1956. Nonparametric statistics for the behavioral sciences. McGraw-Hill Book Co., New York. 1-312.

33. Rodriguez de Turco, E. B., and J. A. Spitzer. 1987. Perturbation of glycerolipid content and biosynthesis in hepatocytes of rats continuously infused with $E$. coli endotoxin. Metab. Clin. Exp. In press.

34. Broekman, M. J., J. W. Ward, and A. J. Marcus. 1981. Fatty acid composition of phosphatidylinositol and phosphatidic acid in stimulated platelets: Persistence of arachidonyl-stearyl structure. Biol. Chem. 256:8271-8274.

35. Capdevila, J., N. Chacos, J. Werringloer, R. A. Prough, and R. W. Estabrook. 1981. Liver microsomal cytochrome P-450 and the oxidative metabolism of arachidonic acid. Proc. Natl. Acad. Sci. USA. 78:5362-5366

36. Oliw, E. H., F. P. Guengerich, and J. A. Oates. 1982. Oxygenation of arachidonic acid by hepatic monooxygenases: isolation and metabolism of four epoxide intermediates. J. Biol. Chem. 257:37713781.

37. Spolarics, Z., B. Tanacs, T. Garzo', J. Mandl, I. Mucha, F Antoni, R. Machovich, and I. Horvath. 1984. Prostaglandin and thromboxane synthesizing activity in isolated murine hepatocytes and nonparenchymal liver cells. Prostaglandins Leucotrienes Med. 16:379-388.

38. Marshall, P. J., R. J. Kulmacz, and W. E. M. Lands. 1987. Constraints on prostaglandin biosynthesis in tissue. J. Biol. Chem. 262:3510-3517.

39. Bar-Tana, J., G. Rose, and B. Shapiro. 1971. The purification and properties of microsomal palmitoyl-coenzyme A synthetase. Biochem. J. 122:353-362.

40. Tanaka T., K. Hosaka, M. Hoshimura, and S. Numa. 1979. Purification and properties of long-chain acyl-Coenzyme-A synthetase from rat liver. Eur. J. Biochem. 98:165-172.

41. Normann, P. T., M. S. Thomassen, E. N. Christiansen, and T. Flatmark. 1981. Acyl-CoA synthetase activity of rat liver microsomes: substrate specificity with special reference to very long-chain and isomeric fatty acids. Biochim. Biophys. Acta. 664:416-427.

42. Philipp, D. P., and P. Parsons. 1979. Isolation and purification of long chain fatty acid coenzyme A ligase from rat liver mitochondria. J. Biol. Chem. 254:10776-10784.

43. Wilson, D. B., S. M. Prescott, and P. W. Majerus. 1982. Discovery of an arachidonoyl coenzyme A synthetase in human platelets. $J$. Biol. Chem. 257:3510-3515.

44. Reddy, T. S., and N. G. Bazan. 1983. Kinetic properties of arachidonoyl-coenzyme A synthetase in rat brain microsomes. Arch. Biochem. Biophys. 226:125-133.

45. Laposata, M., E. L. Reich, and P. W. Majerus. 1985. Arachidonoyl-CoA synthetase. Separation from nonspecific acyl-CoA synthetase and distribution in various cells and tissues. J. Biol. Chem. 260:11016-11020.

46. Pediconi, M. F., E. B. Rodriguez de Turco, and N. G. Bazan. 1983. Effect of postdecapitation ischemia on the metabolism of $\left[{ }^{14} \mathrm{C}\right]-$ arachidonic acid and $\left[{ }^{14} \mathrm{C}\right]$ palmitic acid in mouse brain. Neurochem. Res. 8:835-845.

47. Foster, D. W. 1984. From glycogen to ketones-and back. Diabetes. 33:1188-1199.

48. Christiansen, R. Z. 1977. Regulation of palmitate metabolism by carnitine and glucagon in hepatocytes isolated from fasted and carbohydrate refed rats. Biochim. Biophys. Acta. 488:249-262.

49. Agius, L., M. H. Chowdhury, and K. G. M. M. Alberti. 1986. Regulation of ketogenesis, gluconeogenesis and the mitochondrial 
redox state by dexamethasone in hepatocytes monolayer cultures. Biochem. J. 239:593-601.

50. Neufeld, H. A., J. A. Pace, and F. E. White. 1976. The effect of bacterial infection on ketone concentrations in rat liver and blood and on free fatty acid concentration in rat blood. Metab. Clin. Exp. 25:877-884.

51. Spitzer, J. A. 1985. Effect of endotoxin on lipid metabolism and on adipocytes. In Cellular Biology of Endotoxin. L. J. Berry, editor. Elsevier Science Publishers B. V., Amsterdam. 151-165.

52. Lang, C. H., and J. A. Spitzer. 1987. Glucose kinetics and development of endotoxin-tolerance during long-term continuous endotoxin infusion. Metab. Clin. Exp. 36:469-474.

53. Hagve, T-A., and B. O. Christophersen. 1983. Linolenic acid desaturation and chain elongation and rapid turnover of phospholipids n-3 fatty acids in isolated rat liver cells. Biochim. Biophys. Acta. 753:339-349.

54. Mahadean, S., and F. Suaer. 1974. Effect of trypsin, phospholipases, and membrane-impermeable reagents on the uptake of palmitic acid by isolated rat liver cells. Arch. Biochem. Biophys. 164:185-193.

55. Stremmel, W., and P. D. Berk. 1986. Hepatocellular influx of $\left[{ }^{14} \mathrm{C}\right]$ oleate reflects membrane transport rather than intracellular metabolism or binding. Proc. Natl. Acad. Sci. USA. 83:3086-3090.

56. Ockner, R. K., J. A. Manning, R. B. Poppenhausen, and W. K. L. Ho. 1972. A binding protein for fatty acid in cytosol of intestinal mucosa, liver, myocardium, and other tissues. Science (Wash. DC). 177:56-58.

57. Spector, A. A. 1975 . Fatty acid binding to plasma albumin. $J$. Lipid Res. 16:165-179.

58. Renaud, G., A. Foliot, and R. Ingante. 1978. Increased uptake of fatty acids by the isolated rat liver after raising the fatty acid binding protein concentration with clofibrate. Biochem. Biophys. Res. Commun. 80:327-334.

59. Ockner, R. K., D. A. Burnett, N. Lysenko, and J. A. Manning. 1979. Sex differences in long chain fatty acid utilization and fatty acid binding protein concentration in rat liver. J. Clin. Invest. 64:172-181.

60. Fournier, N., M. Geoffroy, and J. Deshusses. 1978. Purification and characterization of a long chain fatty-acid-binding protein supplying the mitochondrial $\beta$-oxidative system in the heart. Biochim. Biophys. Acta. 533:457-464.

61. Deacive, I. V., and J. A. Spitzer. 1988. Further characterization of a model of chronic endotoxemia in the rat: adenine nucleotide content in liver. Circ. Shock. In press.

62. Holub, B. J. 1985. Nutritional regulation of the composition, metabolism, and function of cellular phosphatidylinositol. In Inositol and phosphoinositides. Metabolism and regulation. J. E. Bleasdale, J. Eichberg, and G. Houser, editors. Humana Press, Clifton, NJ. 31-41.

63. Denning, G. M., P. H. Figard, T. L. Kaduce, and A. A. Spector. 1983. Role of triglycerides in endothelial cell arachidonic acid metabolism. J. Lipid Res. 24:993-1001.

64. Kirschbaum, B. B., and H. B. Bosmann. 1973. Lysolecithin enhancement of glycoprotein: glycosyl transferase activity. FEBS (Fed. Eur. Biochem. Soc.) Lett. 34:129-132.

65. Mookerjea, S., and J. W. M. Yung. 1974. Stimulation of galactosyltransferase in liver microsomes by lysolecithin. Biochem. Biophys. Res. Commun. 57:815-822.

66. Shier, W. T., and J. T. Trotter. 1976. Stimulation of liver microsomal sialyltransferase activity by lysolecithin. FEBS (Fed. Eur. Biochem. Soc.) Lett. 62:165-168.
67. Broekemeier, K. M., P. C. Schmid, H. H. O. Schmid, and D. R. Pfeiffer. 1985. Effect of phospholipase $A_{2}$ inhibitors on ruthenium red-induced $\mathrm{Ca}^{2+}$ release from mitochondria. J. Biol. Chem. 260:105113.

68. Riley, W., and D. R. Pfeiffer. 1986. The effect of $\mathrm{Ca}^{2+}$ and acyl Coenzyme A: lysophospholipid acyltransferase inhibitors on permeability properties of the liver mitochondrial inner membrane. J. Biol. Chem. 261:14018-14024.

69. Haigler, H. T., M. C. Willingham, and I. Pastan. 1980. Inhibitors of ${ }^{125} \mathrm{I}$-epidermal growth factor internalization. Biochem. Biophys. Res. Commun. 94:630-637.

70. Mallorga, P., J. F. Tallman, R. C. Henneberry, F. Hirata, W. T. Strittmatter, and J. Axelrod. 1980. Mepacrine blocks beta-adrenergic agonist-induced desensitization in astrocytoma cells. Proc. Natl. Acad. Sci. USA. 77:1341-1345.

71. Torda, T., I. Yamaguchi, F. Hirata, I. J. Kopin, and J. Axelrod. 1981. Quinacrine-blocked desensitization of adrenoceptors after immobilization stress or repeated injection of isoproterenol in rats. $J$. Pharmacol. Exp. Ther. 216:334-338.

72. Higuchi, H., S. Uchida, K. Matsumoto, and H. Yoshida. 1983. Inhibition of agonist-induced degradation of muscarinic cholinergic receptors by quinacrine and tetracaine: possible involvement of phospholipase $A_{2}$ in receptor degradation. Eur. J. Pharmacol. 94:229-239.

73. Roth, B. L., and J. A. Spitzer. 1987. Altered hepatic vasopressin and $\alpha_{1}$-adrenergic receptors after chronic endotoxin infusion. Am. J. Physiol. 252:E-E.

74. Chernow, B., and B. L. Roth. 1986. Pharmacologic manipulation of the peripheral vasculature in shock: clinical and experimental approaches. Circ. Shock. 18:141-155.

75. McMillan, M., B. Chernow, and B. L. Roth. 1986. Hepatic alpha-_adrenergic receptor alteration in a rat model of chronic sepsis. Circ. Shock. 19:185-193.

76. Baker, C. H., and F. R. Wilmoth. 1984. Microvascular response to $E$. coli endotoxin with altered adrenergic activity. Circ. Shock. 12:165.

77. Rodriguez de Turco, E. B., and J. A. Spitzer. 1987. Impairments in hepatocyte phosphoinositide metabolism in endotoxemia. Metab. Clin. Exp. 36:753-760.

78. Spitzer, J. A., and I. V. Deaciuc. 1987. Inositol trisphosphatedependent $\mathrm{Ca}^{2+}$ release in permeabilized hepatocytes of endotoxic and septic rats. Am. J. Physiol. 252:E-E.

79. Deaciuc, I. V., and J. A. Spitzer. 1986. Rat liver free cytosolic $\mathrm{Ca}^{2+}$ and glycogen phosphorylase in endotoxicosis and sepsis. Am. J. Physiol. 251:R984-R995.

80. Spitzer, J. A., and E. R. de Turco. 1986. Impaired phosphoinositide-mediated signaling in hepatocytes of continuously endotoxemic rats: partial simulation of the effect by a phorbol ester. Sixth International Conference on Cyclic Nucleotides, Calcium and Protein Phosphorylation, Bethesda, MD. (Abstr.)

81. Fredrik Leeb-Lundberg, L. M., S. Cotecchia, A. DeBlasi, M. G. Caron, and R. J. Lefkowitz. 1987. Regulation of adrenergic receptor function by phosphorylation. J. Biol. Chem. 262:3098-3105.

82. McMilliam, M., E. Chernow, and B. L. Roth. 1986. Phorbol esters inhibit $\alpha_{1}$-adrenergic receptor-stimulated phosphoinositide hydrolysis and contraction in rat aorta: evidence for a link between phosphoinositide turnover and vascular contraction. Biochem. Biophys. Res. Commun. 134:970-974. 